Volume and Issues Obtainable at Center for Sustainability Research and Consultancy

Journal of Business and Social Review in Emerging Economies

ISSN: 2519-089X (E): 2519-0326

Volume 6: Issue 2 June 2020

Journal homepage: www.publishing.globalcsrc.org/jbsee

\title{
What Defines Counterfeiting? A Timeline Analysis of the Definitions
}

\author{
${ }^{1}$ Ali Ahmad, ${ }^{2}$ Muhammad Nauman Abbasi, ${ }^{3}$ Omer Farooq \\ ${ }^{1}$ Institute of Management Sciences,Bahauddin Zakariya University, Multan Pakistan, \\ aliahmed.mux@gmail.com \\ ${ }^{2}$ Institute of Management Sciences,Bahauddin Zakariya University, Multan Pakistan, \\ abbasimna@bzu.edu.pk \\ ${ }^{3}$ Air University, Multan Campus, Multan, Pakistan, \\ omer@aumc.edu.pk
}

\begin{tabular}{l}
\hline ARTICLE DETAILS \\
\hline History \\
Revised format: May 2019 \\
Available Online: June 2020 \\
\\
\hline Keywords \\
Counterfeit, Text Analysis, \\
Definition, Counterfeiting, \\
Timeline. \\
\hline
\end{tabular}

JEL Classification

$M 1, M 12$

\begin{abstract}
Though addressed widely by academicians and researchers across the globe, the subject of counterfeiting dates back to historical times of 27BC. In academic literature, the discussion on counterfeit(ing) began a century back when researchers started to define its boundaries through their understanding. Ranging from the classical descriptions on counterfeit, counterfeiting, counterfeit trade and counterfeit product(s), this article intends to use text analysis technique to provide the reader with a summary of the existing academic literature on the aforementioned subjects. It summarizes key definitions from the respective area with a broader aim to bridge the gap in the existing counterfeiting and counterfeit product-related literature by providing a brief (yet ample) list on counterfeit(ing). Moreover, it also identifies the key similarities exiting in the definition set. The article concludes with authors own definition of counterfeiting and counterfeit product(s) based on the conceptualization developed through the understanding of combined definitions from the literature.
\end{abstract}

(C) 2020 The authors, under a Creative Commons AttributionNonCommercial 4.0

Corresponding author's email address: aliahmed.mux@gmail.com

Recommended citation: Ahmad, A., Abbasi M. N., and Farooq, O. (2020). What Defines Counterfeiting? A Timeline Analysis of the Definitions. Journal of Business and Social Review in Emerging Economies, 6(2), 641-650

\section{Introduction}

'Counterfeits are unlawfully made, low-priced products that are produced in such a way that bear resemblance to genuine goods but are inferior in terms of their value, reliability, performance, and resilience (Lai \& Zaichkowsky, 1999; Wilcox, Kim, \& Sen, 2009).'

Several definitions of counterfeit product(s) and counterfeiting have been proposed with all having a central focus on the aspect that the practice classifies to be not only illegal but immoral as well. Based 
on their understanding about different buying contexts, the authors of these definitions have identified counterfeit products from different perspectives.

Surprisingly, little research has been conducted so far in the domain of counterfeiting, counterfeit products and counterfeit purchasing behavior regarding defining a consensual and a generally agreed upon definition on counterfeiting. Using text analysis technique, an attempt has been to provide an overview of the existing academic literature on counterfeiting and counterfeit products by summarizing major definitions extracted from the previous research findings in this area. Based on a comprehensive review of the marketing literature, thirty key definitions have been selected, reviewed and summarized. The purpose is to bridge the gap in the existing literature by providing a brief yet ample list of counterfeit(ing) definitions and highlight the key similarities. Based on the conceptualization, the article proposed a comprehensive definition of counterfeiting for the future concerns.

Several recent papers were searched in Google Scholar based on their relevance to the definitions and defining constructs of counterfeiting. The selected papers were analytically reviewed by the panel of experts with the aim to identify and locate the sources from which different definitions were presented from as early as 1945 to the latest by 2018. Then these definitions were analyzed to explore the key similarities and finally, a new definition is proposed to incorporate a comprehensive outlook of all the definitions presented till 2018.

This write-up begins with a general discussion on counterfeiting and/or counterfeit products. Then, it discusses the historical timeline of the counterfeiting business and sheds light on how it grew to almost all product categories. Thirdly, it debates about the determinants that push customers to original products as compared to counterfeits to give the reader an idea about what possibly the motivational factors come into play to push customers toward originals. The discussion is then followed by a table that provides a snapshot of different definitions presented by different authors in a chronological order followed by a section identifying the key similarities and concludes with the authors' conceptualization of the phenomenon under observation.

\subsection{Counterfeiting}

According to Nordin (2009), counterfeit merchandise comprises of the goods that are produced through illegal means. Not produced by the genuine manufacturer, counterfeits are usually made with low quality standards and components. The counterfeit business comprises of two key sub segment markets titled the deceptive counterfeiting and the non-deceptive counterfeiting. In the former scenario, consumers are unaware of the fact that the product they are purchasing is not a genuine article. In latter, consumers are consciously aware of the point that the product they are purchasing is a counterfeit and still they go for purchasing the very product thus acting as an accomplice in the dark trade of counterfeit (Haie-Fayle \& Hübner, 2007).

Counterfeiting, an immoral and criminological practice that is not a decade or century-old but ages old. Reporting perhaps the first record of such an event in past, Tim Philips, an investigative journalist writes that counterfeiting has been in practice since $27 \mathrm{BC}$. According to him, the history's first counterfeit was none other than a stopper of amphora wine started in France. Serving as an inspiration for the coming times, counterfeiting business flourished massively in terms of its volume (Phillips, 2007). It is estimated that the up-scaling business of counterfeits negatively affected the market of genuine brands and manufacturers with a net worth of \$600bn (Co-operation \& Development, 2016; Shultz II \& Saporito, 1996) and is increasing at an startling rate with every passing day (Norum \& Cuno, 2011). Whether it's music or DVDs, Hermes scarves or Gucci purses, counterfeiting has shown gigantic proliferation in the 1970s and has become a momentous economic problem that is universal and prevalent (A. Zampetakis, 2014; Bian \& Veloutsou, 2007; Harvey \& Ronkainen, 1985). Counterfeiting Intelligence Bureau (2013) in one of its studies stated that the volume of counterfeit products encompassed approximately 5 to 7 percent of world trade and had a worth US \$600 billion annually back in 2013. Sensing the severity of counterfeiting issue, Robin Gray, the executive vice president at 
National Electronic Distributors Association (NEDA) goes to the length of asserting the lucrative state of counterfeit business by saying; "it's more profitable to sell counterfeit electronic components than it is to sell narcotics".

Regardless of the efforts made so far to eradicate counterfeiting from its roots or eliminate it to its minimal, the business continues to thrive in terms of its sales, its customers and number of firms it's engaging. Severe laws have been passed and hundreds of researches, policy papers and commentaries have been published, still, no one seems to be able to grasp the issue from its core. Counterfeits are being manufactured so sophisticatedly that even the brand owners are sometimes unable to differentiate them from the original products without the help of laboratory tests (Chow, 2003). In a research conducted by D'Amato, Belvedere, and Papadimitriou (2019), the results show that though the consumers have the innate ability to differentiate the fake branding elements of a counterfeit i.e. logo, packing etc with much accuracy, however the situation doesn't remains the same particularly if the counterfeit goods manufacturer puts up $\operatorname{logo}(\mathrm{s})$ very momentarily or concisely thus hampering the consumers' ability to find out if the product is counterfeit in actual. Now, it is being suggested that such creative advertisements should be made by the genuine manufacturers that show that if a person uses genuine product, his social prestige elevates, while if the person opts for a copycat version, his image of self-respect gets dented (Nagar, 2020). Moreover, thoughtfully articulated strategies are needed in order to combat the uprising phenomenon of counterfeiting through designing and implementing strong and peerless connections among managers and other players of the value chain of a company's marketing network (Evans, Starr, \& Brodie, 2019) because the legislations that have been made only pertain to the supply side of counterfeits, but do not properly address the demand aspect which is the real culprit side in letting the counterfeit business thrive (Norum \& Cuno, 2011).

\subsection{Counterfeits verses Originals}

Consumers (should and they do) differ significantly in their purchase intentions toward originals and counterfeits. Firstly, those who go for buying original products purchase these for what they mean to them e.g. luxury, whereas those who purchase counterfeits are motivated by the thought of fake prestige they may leverage by purchasing a copycat product without paying for it, i.e. purchasing a counterfeit at a much lower price than its original counterpart (Penz \& Stottinger, 2005). Luxury brands, often considered to be one of the most explicit categories of original product family, are therefore struggling hard because of the increasing product flow of such counterfeit products and a growing number of companies involved in this business (Kaufmann, Petrovici, Gonçalves Filho, \& Ayres, 2016). From wristwatch designers to cloth manufacturers, counterfeits pop-up in almost every product category. Chanel, Burberry, Louis Vuitton, Hermes, Gucci are just to name a few famous brands that have suffered greatly because of the rise of counterfeit market (Yoo \& Lee, 2009). The widespread prevalence of counterfeits in developed and developing countries is a clear signal that the market of counterfeits is thriving. It has been observed that the brands that more liked and accepted well in the society are easy targets for counterfeiting. Therefore, famous brands as quoted above are left with no other option except to bear the loss in terms of lost sales because of their eclectic recognition by a major chunk of buyers (Hussain, Kofinas, \& Win, 2017).

Secondly, customers who wish to elevate their social status without taking any risk become price insensitive or less price sensitive and prefer original products that are priced expensively as compared to their corresponding counterfeits. This desire for a raised self-image and high status consciousness leads to positive purchase intention towards genuine articles as these original products express the wealthy, prosperous and a higher social image to others (Wee, Ta, \& Cheok, 1995). According Yoo and Lee (2009), the experience and satisfaction that the original products provide by their superior quality and high relational and social approval serves as the basis for customers to move away from counterfeits. Original products work better in situations where the customers are actively seeking to uplift their social standing and status. 
Therefore, the manufacturers should not only focus on technological aspects to counter the supply of counterfeits into the market, but also work on the demand side by discouraging the customers to not to purchase the counterfeit products as it may harm their physical as well as psychological well-being (Hussain et al., 2017). According to Wang and Song (2013) the measures undertaken to block counterfeits from the point of production to selling have primarily focused on the supply side and have bluntly ignored the demand side, which is the root cause of the real problem. The reason is quite obvious and that is the ever increasing demand of counterfeits. Thus, it becomes necessary to tackle the demand side of the problem more seriously than the supply side. Interestingly, a recent study has examined the consumption habits and preferences of customers towards counterfeits and original products and have come up with a categorization of four different groups of counterfeit users and genuine brand users i.e. black chameleons, owners of the genuine branded products, owners of counterfeit products, and the genuineness hunters. Based on their behavior, the authors have shown how consumers differ in their intensity towards both extremes of the product originality continuum (Çekirdekci \& Latif, 2019).

The above stated facts and discussion suggest that counterfeiting seem quite lucrative still an illegal and unethical business practice. Hence, proper understanding and standardization of the concept is mandatory for strategy formulation. To attain the objective, the most cited definitions are comprehended in Table -2.1 , aiming to identify the similarities and to proceed with standard definition.

Table 2.1:- Definitions on Counterfeit Products and Counterfeiting

\begin{abstract}
No. Author and Year
1. Section 45 of the Lanham Act [15 C.F.R. Section 1127]
\end{abstract}

2. G Bamossy, DL Scammon (1985)

3. Nash (1989)

4. Kay (1990)

5. (WTO 1994)

\section{Definition}

"A counterfeit is a spurious mark which is identical with or is substantially indistinguishable from a registered mark."

"Counterfeiting can be described as the fraudulent practice of affixing a false trademark to a product. The false trademark then appears superficially indistinguishable from its legitimate counterpart. The purpose of this fraudulent activity is to dupe the consumer into purchasing the counterfeit under the mistaken belief that the product is the genuine article."

"Counterfeit products are sort of forged items affect legitimately produced items by diminishing their value, downgrading their R\&D research, and earning legal revenue."

"Counterfeits are defined as reproduced copies that are identical to the legitimate articles including packaging, trademarks, and labeling."

"According to the Trade-Related Aspects of Intellectual Property Rights (TRIPS) Agreement, counterfeit trademark goods' mean any goods, including packaging, bearing without authorization a trademark that is identical to the trademark validly registered in respect of such goods or that cannot be distinguished in its essential aspects from such a trademark, which thereby infringes the rights of the owner of the trademark in question under the law of the country of importation" 
6. Cordell, Wongtada, and Kieschnick $\operatorname{Jr}(1996)$

7. Chaudhry and Walsh (1996)

8. Lai and Zaichkowsky (1999)

9. Hoon Ang, Sim Cheng, Lim, and Kuan Tambyah (2001)

10. Eisend and Schuchert-Güler (2006)

11. Parloff (2006)

12. Zaichkowsky (2006)

13. Augusto de Matos, Trindade Ituassu, and Vargas Rossi (2007)

14. Penz and Stöttinger (2008)

15. Nordin (2009)

16. Staake, Thiesse, and Fleisch (2009)

17. Wilcox et al. (2009)

18. U.S. GAO. (2010)

19. Bian and Moutinho (2011)

20. Carpenter and Lear (2011)

21. $\operatorname{Lin}(2011)$

22. Jiang and Cova (2012)
"Counterfeits are depicted as propagations of a trademarked brand, incorporating likeness in labeling, trademarks, and packaging, with the expectation that they will be perceived as the original item."

"Counterfeiting is the approach toward production, delivery and offering of items or products that unlawfully reproduce licensed goods in disregard of intellectual and other property rights (copyrights, trademarks, patents, or brand names)."

"Counterfeits are illegal, low priced, and often lower-quality replicas of products that typically possess high brand value."

"Counterfeit products are unauthorized reproductions that appear identical to legitimate products in appearance, including packaging, trademarks, and labeling."

"The act of counterfeiting may not involve production at all, but it could be as simple as falsely labelling or packaging an item that otherwise does not violate IPR."

"Although the counterfeits thus produced continue to be typically constructed of inferior materials, they are often made with the same designs, molds, and specifications as the genuine brands."

"A counterfeit is an imitation of the original version, but with a lower standard of composition and no similar expectation of quality."

"Counterfeiting is an unlawful and unethical act by fraudulently imitating an artistic, or literary work, and even an industrial product without the authorization of its original author or inventor."

"Most counterfeit products are inferior versions of the genuine products."

"Counterfeit merchandise consists of illegal goods with low standards and quality that the genuine manufacturer did not produce."

"Any goods bearing without authorization a trademark which cannot be distinguished in its essential aspects from the trademark registered for such goods."

"Counterfeit products are the replica of original branded products, which have same color, design, packaging and they contain the same logo and/or trademark."

"Counterfeit products are any goods, including packaging bearing without authorization, a trademark that is identical to a trademark validly registered for those goods, or that cannot be distinguished in its essential aspects from such a trademark, and that, thereby, infringes the rights of the owner of the trademark in question."

"A counterfeit product is defined as an illegal replication of a legitimate product, and mimics its labeling, packaging, and trademarks."

"Counterfeit products are defined as identical copies of authentic products and account for at least five percent of the world's trade."

"Counterfeit products include unauthorized use of a brand name or logo, the unauthorized production or sale of goods, and the intentional likeness of brand name merchandise."

"Counterfeiting is the production of copies that are identically packaged, including trademarks and labeling, so as to seem to a consumer that the item is the genuine article." 
23. Spink and Levente Fejes (2012)

24. Tommy (2012)

25. Yoo and Lee (2012)

26. Hoecht and Trott (2014)

27. Noor and Mushi (2016)

28. Ghuman and Merchant (2018)

29. Khandeparkar and Motiani (2018)

30. Liu, Dalton, and Hong (2018)
"Counterfeiting is the copying of a product (and/or package) with the intent to deceive consumers into believing that the product (and/or package) is genuine."

"Counterfeiting is an act of making a product by copying or imitating the physical appearance of an original product to mislead consumers that it is the product of another party. Products that violate trademarks, copyright infringement, and packaging, label, and brand regulations are part of counterfeiting."

"Counterfeiting is an unauthorized representation of a registered genuine trademark that represents a serious threat to legitimate business and brands."

"Counterfeit products are those products that have been shown (usually via some legal body) to infringe an owner's intellectual property rights (IPR), typically a trademark or a patent. These act like parasites that siphon knowledge and intellect from healthy companies that have invested scarce resources in developing products and services with a competitive advantage."

"Counterfeit products are fake replicas of the real product. Counterfeit products are often produced with the intent to take advantage of the superior value of the imitated product."

"Counterfeit goods are defined as illegitimately manufactured or adulterated goods, replica or imitation items, pass-offs, lookalikes, and fake products. Counterfeiting is not just an intellectual property problem; it has also become a criminal issue."

"Counterfeits are exact replicas manage to deceive consumers into believing that they are real."

"Counterfeits products are the fake replicas that cost significantly less than the genuine ones and use a brand name or logo without the owner's authorization."

\subsection{Key Similarities}

Based on the definitions presented in Table - 2.1, similar 'term(s)' (count-wise) have been identified and presented in Table -2.2 for discussion and comprehension. It is worth mentioning that several definitions have been offered in the domain of counterfeiting with the central focus on what is counterfeiting? How it takes place? What should be observed, if included in the product (quality/specification/terms and condition, etc.), to declare it, a counterfeit? In literature, the terms counterfeit, counterfeit products and counterfeiting are used interchangeably. Hence, a simple text analysis of the aforementioned definitions (most cited) of the key authors have been presented, while, some similarities are quite evident. For instance, in term of words, the following terms in greater count;

\section{Table 2.2:- $\quad$ Definitions on Counterfeit Products and Counterfeiting}

\begin{tabular}{|c|c|c|}
\hline Word & Count & Used in context \\
\hline Trademark & 32 & $\begin{array}{l}\text { Counterfeits misleadingly and unlawfully represent the } \\
\text { trademark(s) of original manufacturers. }\end{array}$ \\
\hline Genuine & 16 & Counterfeits copy features of genuine items. \\
\hline (Without) authorization & (12) 10 & $\begin{array}{l}\text { Labels counterfeiting as activity that is carried out without the } \\
\text { authorization from the original manufacturers thus making it } \\
\text { illegal. }\end{array}$ \\
\hline
\end{tabular}


Replicas/Fake $\quad 8 / 6 \quad$ Counterfeits are usually in the form of replicas or fake version of the genuine items.

Unauthorized/Illegal $\quad 8 / 6 \quad$ Describe counterfeiting as a practice that is not permissible by law.

Fake/False 6/4 Counterfeits are the deceitful and untrue type of products.

Deceive $4 \quad$ Counterfeits mislead the customers through their looks.

Inferior/Low $\quad 4 / 4 \quad$ Because of low price, counterfeits are of substandard quality.

\section{Discussion and Conclusion}

The Figure - 2.1 presents the word cloud generated in Nvivo 12 of all the definitions mentioned in the start of this text.

\section{Figure 2.1:- $\quad$ Word Cloud of Counterfeit}

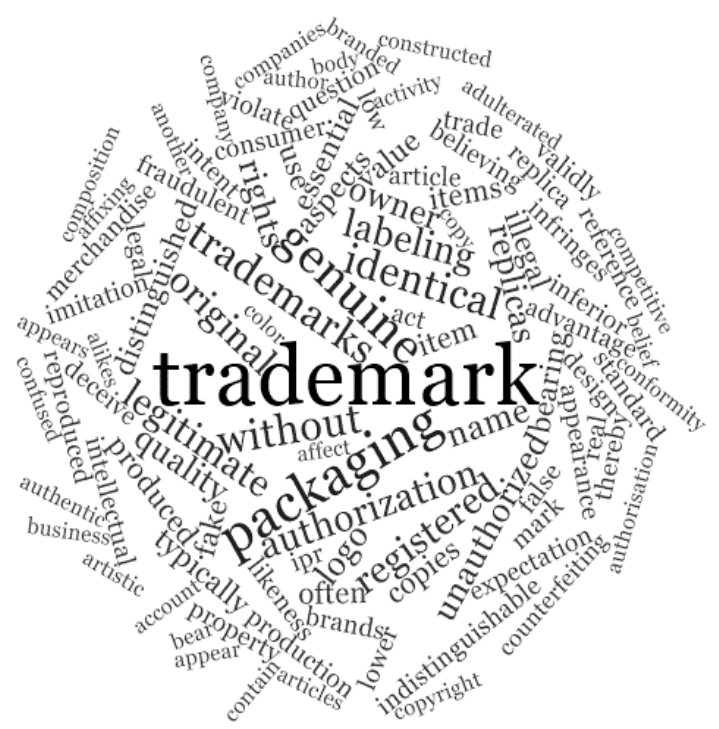

Based on the count cited in the aforementioned table, it can be argued that majority of the definitions of counterfeit products and counterfeiting talk about 'coping trademark, coping features of the genuine products, without authorization, illegal and replicas'. Undoubtedly, the counterfeit products that are produced and sold in the market misleadingly and unlawfully represent the trademark(s) of genuine items. The manufacturers of such products do so without authorization i.e. not taking permission from the original manufacturers of the genuine items and end up producing inferior quality replicas to give a false impression to target customers. Based on the analysis of the definitions quoted above, the following brief definition of 'Counterfeit Products' is synthesized;

"Counterfeit products are the look alike goods that pose themselves as genuine items through their blatant imitation of trademarks, patents and other features of the original product manufacturers."

A detailed definition may be narrated as;

"Produced and sold in an unauthorized, unlawful and a fraudulent way, counterfeits are the inferior quality products that carry low price tags and survive through the selling model of deceiving the customers through their identical features." 
Finally, it can be argued that counterfeiting is an illegal and unethical practice of imitating trademarks of genuine articles with the aim of confusing the customers to mistakenly believe that the product or its source is original. This paper aims to extend the existing body of literature on counterfeiting by synthesizing the classical as well as contemporary literature by presenting an exhaustive set of definition on counterfeit/counterfeiting and comes up with a comprehensive definition of the said constructs to make the reader empathize and grasp the very concept of counterfeiting in an easy way. Though, maximum care has been taken to present most cited definitions, still, future research can be more systematic by incorporating practitioners views.

\section{References}

A. Zampetakis, L. (2014). The emotional dimension of the consumption of luxury counterfeit goods: an empirical taxonomy. Marketing Intelligence \& Planning, 32(1), 21-40.

Augusto de Matos, C., Trindade Ituassu, C., \& Vargas Rossi, C. A. (2007). Consumer attitudes toward counterfeits: a review and extension. Journal of consumer Marketing, 24(1), 36-47.

Bian, X., \& Moutinho, L. (2011). The role of brand image, product involvement, and knowledge in explaining consumer purchase behaviour of counterfeits: Direct and indirect effects. European Journal of Marketing, 45(1/2), 191-216.

Bian, X., \& Veloutsou, C. (2007). Consumers' attitudes regarding non-deceptive counterfeit brands in the UK and China. Journal of Brand Management, 14(3), 211-222.

Carpenter, J. M., \& Lear, K. (2011). Consumer attitudes toward counterfeit fashion products: does gender matter? Journal of Textile and Apparel, Technology and Management, 7(1).

Çekirdekci, Ş. O., \& Latif, F. O. B. (2019). Users and non-users of counterfeits: motivations, emotional outcomes and neutralization processes. Journal of Product \& Brand Management.

Chaudhry, P. E., \& Walsh, M. G. (1996). An assessment of the impact of counterfeiting in international markets: the piracy paradox persists. The Columbia Journal of World Business, 31(3), 34-48.

Chow, D. (2003). Investigating the counterfeit nightmare Procter \& Gamble and Oki Data count the costs. Strategic Direction, 19(3), 9-12.

Co-operation, O. f. E., \& Development. (2016). Trade in Counterfeit and Pirated Goods: Mapping the Economic Impact: OECD Publishing.

Cordell, V. V., Wongtada, N., \& Kieschnick Jr, R. L. (1996). Counterfeit purchase intentions: role of lawfulness attitudes and product traits as determinants. Journal of Business Research, 35(1), 4153.

D’Amato, I., Belvedere, V., \& Papadimitriou, T. (2019). Illegitimate trade in the fashion industry: relevance and counterstrategies in the Italian context. Journal of Business \& Industrial Marketing.

Eisend, M., \& Schuchert-Güler, P. (2006). Explaining counterfeit purchases: A review and preview. Academy of Marketing Science Review, 2006, 1.

Evans, B. P., Starr, R. G., \& Brodie, R. J. (2019). Counterfeiting: conceptual issues and implications for branding. Journal of Product \& Brand Management.

GAO., U. S. (2010). Observations on Efforts to Quantify the Economic Effects of Counterfeit and Pirated Goods. Intellectual Property: United States Government Accountability Office.

Ghuman, K., \& Merchant, H. (2018). Reconfiguring the Marketing Mix to Counter the Counterfeits in the Global Arena Emerging Issues in Global Marketing (pp. 179-204): Springer.

Haie-Fayle, L., \& Hübner, W. (2007). Counterfeiting and piracy: Fakes, facts and figures. Organisation for Economic Cooperation and Development. The OECD Observer(262), 9.

Harvey, M. G., \& Ronkainen, I. A. (1985). International counterfeiters-marketing success without the cost and the risk. Columbia Journal of World Business, 20(3), 37-45.

Hoecht, A., \& Trott, P. (2014). How should firms deal with counterfeiting? A review of the success conditions of anti-counterfeiting strategies. International Journal of Emerging Markets, 9(1), 98119.

Hoon Ang, S., Sim Cheng, P., Lim, E. A., \& Kuan Tambyah, S. (2001). Spot the difference: consumer responses towards counterfeits. Journal of consumer Marketing, 18(3), 219-235. 
Hussain, A., Kofinas, A., \& Win, S. (2017). Intention to purchase counterfeit luxury products: A comparative study between Pakistani and the UK consumers. Journal of International Consumer Marketing, 29(5), 331-346.

Jiang, L., \& Cova, V. (2012). Love for luxury, preference for counterfeits-A qualitative study in counterfeit luxury consumption in China. International journal of marketing studies, 4(6), 1.

Kaufmann, H. R., Petrovici, D. A., Gonçalves Filho, C., \& Ayres, A. (2016). Identifying moderators of brand attachment for driving customer purchase intention of original vs counterfeits of luxury brands. Journal of Business Research, 69(12), 5735-5747.

Kay, H. (1990). Fake's progress. Management Today, 54, 54-59.

Khandeparkar, K., \& Motiani, M. (2018). Fake-love: brand love for counterfeits. Marketing Intelligence \& Planning.

Lai, K. K.-Y., \& Zaichkowsky, J. L. (1999). Brand imitation: do the Chinese have different views? Asia Pacific Journal of Management, 16(2), 179-192.

Lin, Y.-C. J. (2011). Fake stuff: China and the rise of counterfeit goods: Routledge.

Liu, J., Dalton, A. N., \& Hong, J. (2018). Understanding and tackling unethical consumption: The case of counterfeit consumption: HKUST Institute for Emerging Market Studies.

Nagar, K. (2020). Using topdog versus underdog brand biography in advertising: Effects of similarity and consumption decision of non-deceptive counterfeits. Journal of Marketing Communications, 1-21. doi: 10.1080/13527266.2020.1777579

Nash, T. (1989). Only imitation? The rising cost of counterfeiting. Director, 5.

Noor, N. A., \& Mushi, H. M. (2016). Consumer behaviour and counterfeit purchase in the Tanzanian mainland.

Nordin, N. (2009). A study on consumersâ€TM attitude towards counterfeit products In Malaysia. University of Malaya.

Norum, P. S., \& Cuno, A. (2011). Analysis of the demand for counterfeit goods. Journal of Fashion Marketing and Management: An International Journal.

Parloff, R. (2006). Not exactly counterfeit. Fortune, 153(8), 108-+.

Penz, E., \& Stottinger, B. (2005). Forget the Areal@ thingbtake the copy! An explanatory model for the volitional purchase of counterfeit products. ACR North American Advances.

Penz, E., \& Stöttinger, B. (2008). Original brands and counterfeit brands - do they have anything in common? Journal of Consumer Behaviour: An International Research Review, 7(2), 146-163.

Phillips, T. (2007). Knockoff: The Deadly Trade in Counterfeit Goods: The True Story of the World's Fastest Growing Crimewave: Kogan Page Publishers.

Shultz II, C. J., \& Saporito, B. (1996). Protecting intellectual property: Strategies and recommendations to deter counterfeiting and brand piracy in global markets. The Columbia Journal of World Business, 31(1), 18-28.

Spink, J., \& Levente Fejes, Z. (2012). A review of the economic impact of counterfeiting and piracy methodologies and assessment of currently utilized estimates. International Journal of Comparative and Applied Criminal Justice, 36(4), 249-271.

Staake, T., Thiesse, F., \& Fleisch, E. (2009). The emergence of counterfeit trade: a literature review. European Journal of Marketing, 43(3/4), 320-349.

Tommy, H. (2012). Pengaruh Faktor Sosial Dan Personal Terhadap Sikap dan Niat Beli Konsumen untuk Barang Fashion Palsu di Kota Denpasar dan Kabupaten Badung. Tesis. Jurusan Magister Manajemen Program Studi Manajemen Universitas Udayana Denpasar, Bali.

Wang, Y., \& Song, Y. (2013). Counterfeiting: Friend or foe of luxury brands? An examination of Chinese consumers' attitudes toward counterfeit luxury brands. Journal of Global Marketing, 26(4), 173-187.

Wee, C.-H., Ta, S.-J., \& Cheok, K.-H. (1995). Non-price determinants of intention to purchase counterfeit goods: An exploratory study. International Marketing Review, 12(6), 19-46.

Wilcox, K., Kim, H. M., \& Sen, S. (2009). Why do consumers buy counterfeit luxury brands? Journal of marketing research, 46(2), 247-259.

Yoo, B., \& Lee, S.-H. (2009). Buy genuine luxury fashion products or counterfeits? ACR North 
American Advances.

Yoo, B., \& Lee, S.-H. (2012). Asymmetrical effects of past experiences with genuine fashion luxury brands and their counterfeits on purchase intention of each. Journal of Business Research, 65(10), 1507-1515.

Zaichkowsky, J. L. (2006). The psychology behind trademark infringement and counterfeiting: Psychology Press. 